\title{
Relationship Between Passion and Motivation for Gaming in Players of Massively Multiplayer Online Role-Playing Games
}

\author{
Héctor Fuster, MSc, Andrés Chamarro, $\mathrm{PhD},{ }^{2}$ Xavier Carbonell, $\mathrm{PhD}$, and Robert J. Vallerand, $\mathrm{PhD}^{3}$
}

\begin{abstract}
Passion represents one of the factors involved in online video gaming. However, it remains unclear how passion affects the way gamers are involved in massively multiplayer online role-playing games (MMORPGs). The objective of the present study was to analyze the relationships between passions and motivations for online game playing. A total of 410 MMORPG players completed an online questionnaire including motives for gaming and the Passion Scale. Results indicated that passionate gamers were interested in relating with others through the game and exhibited a high degree of interest in discovery of the game, gaining leadership and prestige but little interest in escape from reality. However, some differences were observed with respect to the role of the two types of passion in the different types of motivation. Specifically, harmonious passion (HP) predicted higher levels of exploration, socialization, and achievement, in that order, while obsessive passion (OP) predicted higher levels of dissociation, achievement, and socialization. The present findings suggest that HP and OP predict different ways of engaging in MMORPGs and confirm that passion is a useful construct to help understand different motivational patterns demonstrated by MMORPG players.
\end{abstract}

\section{Introduction}

$\mathbf{V}$ IDEO GAMES CONSTITUTE ONE OF THE leisure activity sectors that has grown the most in the last decade. ${ }^{1}$ One of the greatest contributors to this growth has been the massively multiplayer online role-playing games (MMORPGs), a genre that includes those online games involving a computerbased simulated environment through which geographically separated individuals interact by means of virtual representations (avatars) and have the ability to use and create objects. Video games of this type bring together more than 22 million players worldwide. ${ }^{2}$

Given the magnitude and constant growth of MMORPGs, it is necessary to determine the mechanisms structuring this activity. In this respect, there has been research into player characteristics, ${ }^{3,4}$ addiction, ${ }^{5,6}$ positive and negative impacts of playing, ${ }^{7}$ and personality profiles of players. ${ }^{8}$

A recent review of the literature has revealed the diversity of players' motives for playing MMORPGs. ${ }^{7}$ According to Yee, players play MMORPGs to socialize with others, to gain achievement, or to immerse into an alternative world. ${ }^{9}$ Demetrovics et al. ${ }^{10}$ identified seven motivations: social, escape, competition, coping, skill development, fantasy, and recreation. These dimensions overlap with those found by Yee. A subsequent study by Fuster et al. identified four intrapersonal and interpersonal motives: socialization (i.e., to make friends and provide mutual support while playing the game), exploration (i.e., to discover the virtual environment and participate in the mythology of the game and the adventures the game offers), achievement (i.e., seeking to achieve one's goals during the game), and dissociation (i.e., to avoid/escape reality while playing the game). ${ }^{11}$ Socialization and achievement are similar to two of the factors identified by Yee, ${ }^{9}$ but exploration and dissociation split up Yee's immersion factor. ${ }^{8}$

Some studies have regarded MMORPGs as opportunities for making contact and socialization with other people. ${ }^{12-15}$ One of the main components of the motivation for socialization is that of making new friends, whether through ad hoc groups or through formal hierarchical groups, known as guilds. ${ }^{16}$ Socialization in the context of a MMORPG involves resolving challenges or quests that the game presents with the help of other people, jointly discovering the features and adventures offered by the MMORPG and, consequently,

\footnotetext{
${ }^{1}$ Department of Psychology, Universidad Ramon Llull, Barcelona, Spain.

${ }^{2}$ Department of Psychology, Universidad Autónoma de Barcelona, Bellaterra, Spain.

${ }^{3}$ Department of Educational and Counselling Psychology, McGill University, Montreal, Canada.
} 
sharing in achievements made by the guild as a whole. ${ }^{9,14}$ In relation to this social aspect of playing, Longman et al. showed that social support among World of Warcraft players was associated with fewer negative psychological symptoms and with greater well-being. ${ }^{17}$

Boyle et al. analyzed the multifactorial nature of engagement in digital entertainment games, including MMORPGs, and recommended the use of rigorous theoretical models because previous research tends to comprise lists of features rather than coherent theoretical models. ${ }^{7}$

The Dualistic Model of Passion is a new attempt to explain how individuals experience inclination toward an activity in which they invest time and energy. ${ }^{18}$ The model distinguishes between harmonious passion (HP) and obsessive passion (OP). Both types of passion refer to the tendency to engage in an activity that the person likes or even loves and is important to them, to the point of becoming an activity involving identification, in which they invest considerable time and energy. HP involves an interest to engage in some activity through their own volition that does not decline while engaged in the activity. OP, on the other hand, refers to an uncontrollable urge forcing the individual to engage in the activity that one loves. Recent studies support the use of the Dualistic Model of Passion to understand how people engage in online video gaming and its effects. ${ }^{19-21}$ In general, studies on passion reveal that despite the fact that both forms of passion are usually present while video gaming, only HP is positively related to wanting to play as well as game enjoyment, postplay energy, and self-realization. ${ }^{22}$ Utz et al. showed that HP was positively related to socialization. ${ }^{21} \mathrm{OP}$, on the other hand, predicts the negative aspects associated with video gaming, such as the urge to play as well as the amount of time spent playing, states of postgame tension, and low levels of enjoyment of the game. ${ }^{23-25}$ These studies provide support for the generalizability of the Dualistic Model of Passion and suggest that passion represents one of the factors involved in online video gaming. However, it remains unclear how passion is related to the way gamers are involved motivationally in digital gaming because HP and OP may be activity specific. ${ }^{24}$

Previous studies have used motivations for analyzing gamers engagement and styles of play, ${ }^{3,25,26}$ and others have examined the independent effects of the two types of passion, but no studies have analyzed how online gamers with different passions experience different motivations while playing. Also, as Vallerand et al. proposed, passion may influence the contextual-motivational processes that are central for understanding behaviour. ${ }^{27}$ However, the role of passion in predicting motivations experienced when engaged in MMORPGs represents a key question ${ }^{28}$ that to date has not yet been addressed. The purpose of the present study was to study the relationship between passion and motivations for online video gaming. On the basis of the above, we propose exploring how the two types of passion are related to the different motivations for engaging in MMORPGs identified by Fuster et al. ${ }^{11}$

Previous research has shown that HP is related to cooperating to achieve common goals in game missions and social interactions, ${ }^{24}$ and unrelated to escaping from life situations. $^{20}$ In light of the above, it was hypothesized that HP would be positively related to exploration, socialization, and achievement, but unrelated to dissociation. On the other hand, in light of the fact that OP is positively related to

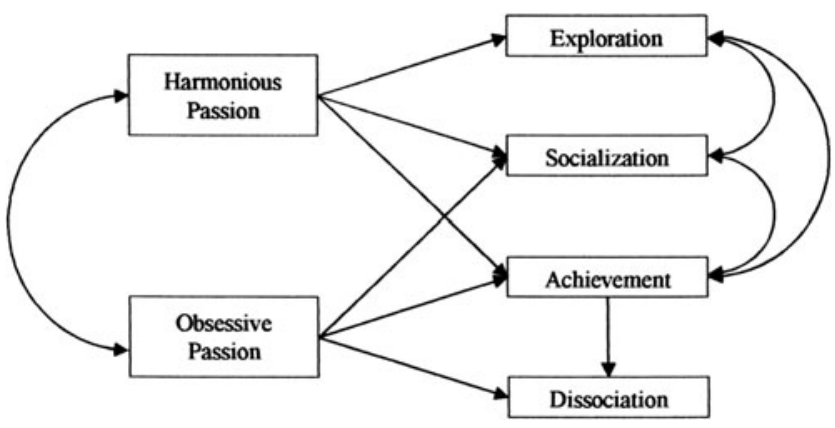

FIG. 1. Hypothesized path model of massively multiplayer online role-playing game (MMORPG) playing in terms of motivations and passions.

escaping from life situations, ${ }^{20}$ and either unrelated or negatively related to relationships, ${ }^{29}$ it was hypothesized that OP would be positively related to dissociation, achievement, and socialization, but unrelated to exploration (see Fig. 1).

\section{Method}

\section{Participants}

Sampling was carried out for 1 month via MMORPG gaming communities. A message was posted in the general forum of each community that invited gamers to respond to an online questionnaire. There was also a request to forward the post to other players. During the sampling period, a total of 430 Spanish-speaking MMORPG players between 16 and 45 years of age completed the questionnaire (410 men, 20 women). In light of the low number of women, female responses were not taken into account due to their low representation in the sample $(4.87 \%)$. The final sample consisted of 410 male players with a mean age of 26.49 years $(S D=6.78)$. Participants had been playing MMORPGs on average for 6.06 years $(S D=3.04)$ and had been playing their current MMORPG for an average of 2.56 years $(S D=2.29)$. The most popular games were World of Warcraft (32\%), Lord of the Rings Online (22\%), Rift (16.6\%), EVE Online (11.5\%), Aion (5.1\%), DC Universe Online (4.1\%), and other less popular MMORPGs $(9.8 \%)$. The average number of hours played per week was $22.38(S D=13.82) ; 18.5 \%$ spent 10 hour or less per week playing MMORPG, $37.8 \%$ spent between 11 and 20 hours, $22.4 \%$ between 21 and 30 hours, $10.5 \%$ between 31 and 40 hours, and $10.7 \%$ of players spent more than 40 hours playing per week.

\section{Instruments}

Demographics. The questionnaire asked for information about gender, age, which game they played, and how often they played (distinguishing weekdays and weekends).

The Passion Scale. The Passion Scale was used to measure passion in regard to the game. ${ }^{18}$ The instrument consists of two scales and four criterion items;, all of which are evaluated using 7-point Likert items. The criterion items establish the degree to which the player likes the activity (item 1 ), values the activity (item 2), dedicates time and energy to it (item 3), and considers it a passion (item 4). In the present study, these four items were correlated $(\alpha=0.700)$. The first 
Table 1. Descriptive Statistics and Correlation Coefficients for the Massively Multiplayer Online Games Motivations Scale (MMO-MS) and the Passion Scale

\begin{tabular}{|c|c|c|c|c|c|c|c|c|c|c|}
\hline & Mean & SD & $\alpha$ & 1 & 2 & 3 & 4 & 5 & 6 & 7 \\
\hline 1 Socialization & 10.74 & 4.40 & 0.815 & - & $0.317 * *$ & $0.409 * *$ & $0.247 * *$ & $0.305 * *$ & $0.184 * *$ & $0.243 * *$ \\
\hline 2. Exploration & 25.64 & 5.93 & 0.752 & & - & $0.404 * *$ & $0.123^{*}$ & $0.438 * *$ & 0.072 & $0.327 * *$ \\
\hline 3. Achievement & 18.00 & 7.32 & 0.815 & & & - & $0.385 * *$ & $0.259 * *$ & $0.342 * *$ & $0.302 * *$ \\
\hline 4. Dissociation & 20.94 & 8.93 & 0.835 & & & & - & $0.137 *$ & $0.689 * *$ & $0.541 * *$ \\
\hline 5. Harmonious passion & 26.36 & 6.65 & 0.734 & & & & & - & $0.171 * *$ & $0.422 * *$ \\
\hline 6. Obsessive passion & 13.41 & 7.24 & 0.853 & & & & & & - & $0.575^{* *}$ \\
\hline 7. Passion criteria & 17.01 & 4.99 & 0.700 & & & & & & & - \\
\hline
\end{tabular}

Correlation is significant at the $* 0.05$ level (two-tailed); $* * 0.001$ level (two-tailed).

$S D$, standard deviation.

subscale (six items) measures HP $(\alpha=0.734)$, while the second (six items) measures OP $(\alpha=0.853)$. The Passion Scale has been shown in the past to have excellent psychometric properties. ${ }^{30}$ In the present study, acceptable levels of internal consistency were found for the Passion subscales. Cronbach's alphas of the subscales are presented in Table 1 and were adequate.

Massively Multiplayer Online Games Motivations Scale (MMO-MS). This scale was used to measure motivations involved in playing with the different virtual worlds. The MMO-MS is an adaptation of the World of Warcraft Inventory, ${ }^{11}$ adapted to each player's reference virtual world. The MMO-MS consists of 20 items divided into four subscales: Socialization (three items), Exploration (five items), Achievement (five items), and Dissociation (seven items). Participants were requested to indicate for their favorite MMORPG and their degree of agreement with each item. Items were evaluated using a 7-point Likert scale. Cronbach's alphas of the subscales are presented in column 4 of Table 1. All Cronbach's alpha coefficients were adequate. A confirmatory factor analysis yielded an acceptable goodness of fit index for a four-factor model reflecting the four motivation subscales: $\left(\chi^{2}(164)=461.11 ; p<0.01 ; \mathrm{CFI}=0.94\right.$; $\mathrm{IFI}=0.94 ;$ RMSEA $=0.06[0.000-0.070])$.

\section{Procedure}

Sampling was achieved by contacting Spanish-speaking forums dedicated to various MMORPGs: Aion-ESP, RiftESP, JuegaEnRed, DCUO Hispano, WoW-ESP, Guild Wars Latino, EVE-Online.es, and Comunidad Hispana. Players were invited to participate by a message posted in the general or "off-topic" sections of the various forums. The message included a brief explanation of how to answer the questionnaire and an image that contained a link to it. The message also included a request to forward the questionnaire to other players. The scales were adapted to permit implementation using the LimeSurvey free software (www. limesurvey.org/), which allows the dynamic design of questionnaires in PHP and CSS formats. When a participant accessed the questionnaire, they were shown a page titled "Informed Consent" that stated that by clicking the "next" button, they agreed to participate in the research and answer the questions. This page also informed the participants that their responses would remain anonymous and that they could stop their participation voluntarily at any time without penalty. Duplicate participation was controlled for via "cook- ies" and IP filtering. Answers were recorded in a $M y S Q L$ database hosted on the servers provided by LimeSurvey. Responses were imported from the LimeSurvey host servers to a database compatible with the statistical packages IBM SPSS Statistics v19.0 (IBM Corp., Armonk, NY) and EQS 6.1 (Multivariate Software, Inc., Encino, CA). Path analysis, with maximum likelihood estimation, was used to test the hypothesized model. Conventional criteria were used to assess the fit of the hypothesized model to the observed data. Adequate fit was inferred when TLI and CFI were $>0.95$, RMSEA was $<0.06$, and SRMR was $<0.08 .^{31}$

\section{Results}

The means and standard deviations as well as the intercorrelations of the measures are displayed in Table 1. HP and OP correlated together only weakly. In general, gamers scored higher on HP than on OP.

The hypothesized model was tested by a path analysis where HP was hypothesized to be positively related to exploration, relationships, and achievement but unrelated to dissociation, while OP was hypothesized to be positively related to dissociation, achievement, and socialization but unrelated to exploration. In addition, covariances were freed between the two types of passion and among all motivations except exploration and socialization on the one hand and dissociation on the other. Due to the crosssectional design and the potential for multiple models to provide adequate fit to the data, a theoretically viable alternative model was previously tested. In this alternative model, HP is a positive predictor of socialization and exploration, two motives with positive consequences, and OP is a positive predictor of achievement and dissociation, which are expected to be motives with negative consequences. In this model, all the motives are assumed to be correlated. Additionally, a replication of the proposed model was carried with World of Warcraft players and players of the other MMORPGs.

Results are presented in Figure 2. Fit indexes demonstrated that the theoretically alternative model did not show an adequate fit. However, the hypothesized model showed an adequate fit to the data $\left(\chi^{2}=4.591(4) ; p>0.05 ; \mathrm{CFI}=0.99\right.$; $\mathrm{GFI}=0.99 ; \mathrm{NFI}=0.99 ; \mathrm{NNFI}=0.99 ; \mathrm{RMSEA}=0.01[0.000-$ 0.079]). Fit indexes for the hypothesized model in separate samples indicate that the model fits well for different games (see Table 2).

The $R^{2}$ statistic indicated that $11.2 \%$ of the variance in Socialization, $19.2 \%$ of the variance in Exploration, $16.7 \%$ 


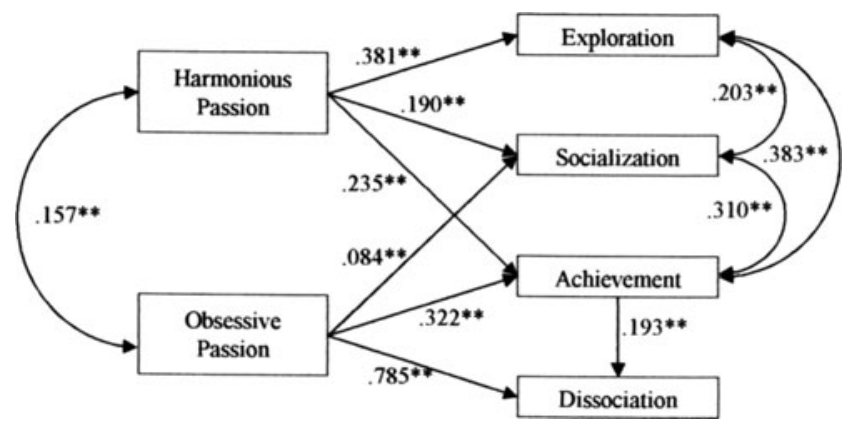

FIG. 2. Diagram of the conceptual model and the results of path analysis.

of the variance in Achievement, and $50.1 \%$ of the variance in Dissociation were explained by the model.

As hypothesized, significant paths $(p<0.001)$ were observed between HP and exploration $(\beta=0.381)$, socialization $(\beta=0.190)$, and achievement $(\beta=0.235)$. On the other hand, significant paths were obtained between OP and dissociation $(\beta=0.785)$, achievement $(\beta=0.322)$, and socialization $(\beta=0.084)$.

\section{Discussion}

Vallerand et al. proposed that passion may influence the contextual-motivational processes that are central for understanding behavior, ${ }^{27}$ and Wang et al. concluded that passion could help our understanding of motivation in digital gaming. ${ }^{24}$ However, to date, studies have not analyzed how passions may affect people's motivations when engaged in playing MMORPGs. Thus, the major goal of the present study was to analyze how passion relates to motives for playing MMORPGs. As expected, results indicated that HP was mainly positively related to exploration and socialization as well as achievement. On the other hand, OP was mainly related to dissociation and achievement and weakly to socialization.

These results suggest that both constructs-motivation and passion - can be integrated into an explanatory model of gaming behavior, in which HP and OP guide the various motivations experienced while playing online gaming. Thus, as expected, it was found that exploration, socialization, and achievement are motivations triggered by HP, whereas those of dissociation, achievement, and, to a lesser extent, socialization are experienced when engaging in MMORPGs out of OP. So, as expected, HP facilitates the experience of more adaptive forms of motivation, while OP leads to the experience of both adaptive (achievement and socialization) and less adaptive (dissociation) forms of motivation.
These findings are in line with those of Wang et al., who concluded that those players who form part of a guild oriented toward social interaction are less likely to develop an addiction to playing, something that is associated with an OP. ${ }^{24}$ Although MMORPGs represents an open experience in which players direct their activity toward challenges that can be either casual or more achievement oriented, ${ }^{12,32}$ the game is usually developed within the limits resulting from the motivations implicit in its design - mainly socialization and exploration, with achievement being secondary to these. It may thus be inferred that forms of playing motivated by socialization and exploration predict positive consequences. ${ }^{11}$ Unsurprisingly, Longman et al. concluded that socialization in playing MMORPGs leads to greater wellbeing. ${ }^{17}$

The relationship between OP and socialization can be explained by a phenomenon observed by Shen and Williams who found that despite socialization in MMORPG being a positive factor, in some cases it could develop to a point where players preferred online encounters to "face-to-face" contact. ${ }^{33}$ In this way, users avoid physical relations and satisfy their social needs through a virtual world. Moreover, Snodgrass et al. claim that dissociation is part of MMORPGs through what they term "technologies of absorption,",34 and which may lead to either positive or negative effects depending on the context in which the activity is engaged. Thus, Griffiths and Wan and Chiou state that MMORPGs can be used as a way of counteracting deficiencies in players' lives, and therefore the need to avoid reality may be a need to avoid problems that the player is unable or unwilling to face. ${ }^{35-37}$

The present findings indicate that HP and OP both help to predict different ways of engaging in MMORPGs. Thus, the results are in line with those of Stoeber et al. and Wang and $\mathrm{Chu},{ }^{20,23}$ and confirm that the Dualistic Model of Passion helps to differentiate between two types of players who are equally passionate about the game but who show different motivational patterns and, as result, who experience different consequences. HP is related to motivational forces to engage voluntarily in an activity, where the player can control their level of participation, display a flexible persistence, and experience adaptive outcomes. OP can generate excitement derived from engagement, but becomes overpowering and difficult to regulate. ${ }^{38}$ As a consequence, OP has been shown to be associated with personal dissatisfaction, psychological problems, behavioral problems, low self-realization, and physical problems. ${ }^{19,22}$ Thus, OP for online gaming promotes online relationships but poorer outcomes. ${ }^{21}$

However, our results support previous findings that have evidenced the adaptive role of HP. ${ }^{39}$ As Curran et al..$^{40}$ have

Table 2. Fit of Path Models

\begin{tabular}{lcccccc}
\hline & $\chi^{2}(\mathrm{df})$ & $\chi^{2} / \mathrm{df}$ & CFI & NNFI & RMSEA [90\% CI] & AIC \\
\hline M1 & $30.66(4) *$ & 7.65 & 0.95 & 0.83 & $0.12[0.08-0.17]$ & 22.66 \\
M2 & $4.59(4) n s$ & 1.14 & 0.99 & 0.99 & $0.01[0.00-0.07]$ & -3.40 \\
M3 & $6.11(4) n s$ & 1.52 & 0.98 & 0.95 & $0.06[0.00-0.15]$ & -1.88 \\
M4 & $2.60(4) n s$ & 0.65 & 1 & 1 & $0.00[0.00-0.07]$ & -5.39 \\
\hline
\end{tabular}

Note. M1: In this model, HP have a direct pathway to exploration and socialization, and OP to achievement and dissociation; the four motives are intercorrelated. M2: The proposed model. M3: The proposed model tested only with World of Warcraft players ( $n=131)$. M4: The proposed model tested only with players of other MMORPGs $(n=279)$. ${ }^{*} p<0.05 ; n s$, not significant. 
argued, this can be understood in the sense of its potential for mitigating negative effects. So, interventions could then focus on using MMORPGs in coexistence with other socialization and leisure activities. With regard to OP, it seems to be related to maladaptive forms of gaming, dedicating a high number of hours with the main interest being to escape from reality. Thus, it that is not the number of hours played per se that may be problematic with respect to MMORPGs but the passion that fuels game playing. Given that features of the subjective experience of gaming, such as presence, flow, and immersion, may lead to negative outcomes, 7,41 their relationship with OP should be analyzed. Moreover, because players who develop an OP for the game appear to be unable to regulate the time they spend playing, in line with Utz et al.'s suggestion, future research should assess whether OP represents a screening tool for problematic forms of play. ${ }^{21} \mathrm{We}$ note that these results have been obtained on a sample of players of different MMORPGs, which would validate the usefulness of the Dual Model of Passion beyond specific games.

Certain limitations of the present study deserve to be mentioned. One is that the data were cross-sectional. Clearly, there is a need for longitudinal studies charting the evolution of game playing motivation as a function of passion. Second, it is not known whether the players with high scores for OP were really addicted to the game. Given that the differentiation between gaming addiction and high engagement is still not clear, future studies should focus on this issue. ${ }^{42}$ Thus, future research would do well to relate OP and addiction in clinical samples.

Moreover, another limitation of this study was the fact that females could not be taken into account in the data analyses. Other researchers have determined that the video game phenomenon is profoundly gendered, and the number of male players is significantly greater than that of women. ${ }^{43}$ Moreover, previous research with players has shown that these differences are even greater among Spanish-speaking MMORPG players, suggesting that this is due to the late arrival of the MMORPG genre to the Spanish video game market. ${ }^{3}$ Future research should take into consideration achieving a representative female sample.

In conclusion, the passion-motivation model that was empirically substantiated in the present research proposes a framework and a context through which the gamer and his activity can be understood in a more comprehensive fashion. This research also suggests that the Dualistic Model of Passion may be useful in designing programs to promote a more adaptive way to engage in MMORPGs and, in turn, to experience adaptive outcomes from one's engagement in such games.

\section{Author Disclosure Statement}

No competing financial interests exist.

\section{References}

1. Siwek S. (2010) Video games in the 21st century: the 2010 report. www.theesa.com/facts/pdfs/VideoGames21 stCentury_ 2010.pdf (accessed Mar. 2013).

2. Van Geel I. (2012) MMOData Charts versión 3.3. www.mmodata.net (accessed Feb. 2013).
3. Fuster $\mathrm{H}$, Carbonell $\mathrm{X}$, Chamarro A, et al. Interaction with the game and motivation among players of massively multiplayer online role-playing games. Spanish Journal of Psychology 2013; 16:1-8.

4. Meredith A, Hussain Z, Griffiths M. Online gaming: a scoping study of massively multi-player online role playing games. Electronic Commerce Research 2009; 9:3-26.

5. Billieux J, Channal J, Khazaal Y, et al. Psychological predictors of problematic involvement in massively multiplayer online role-playing games: illustration in a sample of male cybercafé players. Psychopathology 2011; 44:165-171.

6. Hussain Z, Griffiths MD. Excessive use of massively multiplayer online role-playing games: a pilot study. International Journal of Mental Health \& Addiction 2009; 7: 563-571.

7. Boyle EA, Connolly TM, Hainey T, et al. Engagement in digital entertainment games: a systematic review. Computers in Human Behavior 2012; 28:771-780.

8. Graham KT, Gosling SD. Personality profiles associated with different motivations for playing World of Warcraft. CyberPsychology, Behavior, \& Social Networking 2013; 16:1-5.

9. Yee N. The demographics, motivations and derived experiences of users of massively-multiuser online graphical environments. Presence: Teleoperators \& Virtual Environments 2006; 15:309-329.

10. Demetrovics Z, Urban R, Nagygyörgy K, et al. Why do you play? The development of the motives for online gaming questionnaire (MOGQ). Behavior Research Methods 2011; 43:814-825.

11. Fuster H, Oberst U, Griffiths M, et al. Psychological motivation in online role-playing games: a study of Spanish World of Warcraft players. Anales de Psicología 2012; 28:274-280.

12. Cole H, Griffiths M. Social interactions in massively multiplayer online role playing games. CyberPsychology \& Behavior 2007; 10:575-583.

13. Ducheneaut N, Yee N. (2008) Collective solitude and social networks in World of Warcraft. In Romm-Livermore C, Setzekorn S, eds. Social networking communities and e-dating services: concepts and implications. New York: Information Science Reference, pp. 78-100.

14. Ducheneaut N, Yee N, Nickell E, et al. (2006) Alone together? Exploring the social dynamics of massively multiplayer online games. Proceedings of CHI 2006. Montreal: ACM Press, pp. 407-416.

15. Lortie C, Guitton M. Social organization in virtual settings depends on proximity to human visual aspect. Computers in Human Behavior 2011; 27:1258-1261.

16. Williams D, Ducheneaut N, Ciong L, et al. From tree house to barracks: the social life of guilds in World of Warcraft. Games \& Culture 2006; 1:338-361.

17. Longman H, O'Connor E, Obst P. The effect of social support derived from World of Warcraft on negative psychological symptoms. CyberPsychology \& Behavior 2009; 12:563-566.

18. Vallerand R, Balanchard C, Mageau G, et al. Les passions de l'âme: on obsessive and harmonious passion. Journal of Personality \& Social Psychology 2003; 85:756-767.

19. Lafrenière M., Vallerand R., Donahue E, et al. On the costs and benefits of gaming: the role of passion. CyberPsychology \& Behavior 2009; 12:285-290.

20. Stoeber J, Harvey M, Ward JA, et al. Passion, craving, and affect in online gaming: predicting how gamers feel when 
playing and when preventing from playing. Personality \& Individual Differences 2011; 51:991-995.

21. Utz S, Jonas KJ, Tonkens E. Effects of passion for massively multiplayer online role-playing games on interpersonal relationships. Journal of Media Psychology 2012; 24:77-86.

22. Przybylski A, Weinstein N, Ryan R, et al. Having to versus wanting to play: background and consequences of harmonious versus obsessive engagement in video games. CyberPsychology \& Behavior 2009; 12:485-492.

23. Wang $\mathrm{C}$, Chu Y. Harmonious passion and obsessive passion in playing online games. Social Behavior \& Personality 2007; 35:997-1006.

24. Wang C, Khoo A, Liu W, et al. Passion and intrinsic motivation in digital gaming. CyberPsychology \& Behavior 2008; 11:39-45.

25. Wang C, Liu W, Chye S, et al. Understanding motivation in internet gaming among Singaporean youth: the role of passion. Computers in Human Behavior 2011; 27:1179-1184.

26. Billieux J, et al. Why do you play World of Warcraft? An in-depth exploration of self-reported motivations to play online and in-game behaviours in the virtual world of Azeroth. Computers in Human Behavior 2013; 1:103-109.

27. Vallerand RJ, Rousseau FL, Grouzet FME, et al. Passion in sport: a look at determinants and affective experiences. Journal of Sport \& Exercise Psychology 2006; 28:454-478.

28. Vallerand RJ. From motivation to passion: in search of the motivational processes involved in a meaningful life. Canadian Psychology/Psychologie Canadienne 2012; 53:43-52.

29. Philippe FL, Vallerand RJ, Houlfort N, et al. Passion for an activity and quality of interpersonal relationships: the mediating role of emotions. Journal of Personality \& Social Psychology 2010; 98:917-932.

30. Vallerand R. (2010) On passion for life activities: the Dualistic Model of Passion. In Zanna MP, ed. Advances in experimental social psychology. New York: Academic Press, vol. 42, pp. 97-193.

31. Hu L, Bentler PM. Cutoff criteria for fit indexes in covariance structure analysis: conventional criteria versus new alternatives. Structural Equation Modeling 1999; 6:1-55.

32. Westwood D, Griffiths M. The role of structural characteristics in video-game play motivation: a Q-Methodology study. CyberPsychology, Behavior, \& Social Networking 2010; 13:581-585.

33. Shen C, Williams D. Unpacking time online: connecting Internet and massively multiplayer online game use with psychosocial well-being. Communication Research 2010, 38:123-149.
34. Snodgrass J, Lacy M, Dengah F, et al. Magical flight and monstrous stress: technologies of absorption and mental wellness in Azeroth. Culture, Medicine \& Psychiatry 2011; 35:26-62.

35. Griffiths M. The role of context in online gaming excess and addiction: some case study evidence. International Journal of Mental Health \& Addiction 2010; 8:119-125.

36. Wan C, Chiou W. Psychological motives and online games addiction: a test of flow theory and humanistic needs theory for Taiwanese adolescents. CyberPsychology \& Behavior 2006; 9:317-324.

37. Wan C, Chiou W. Why are adolescents addicted to online games? An interview study in Taiwan. CyberPsychology \& Behavior 2006; 9:762-766.

38. Vallerand R, Mageau GA, Elliot AJ, et al. Passion and performance attainment in sport. Psychology of Sport \& Exercise 2008; 9:373-392.

39. Vallerand RJ, Miquelon P. (2007) Passion for sport in athletes. In Lavallée D, Jowett S, eds. Social psychology in sport. Champaign, IL: Human Kinetics, pp. 249-262.

40. Curran Th, Appleton PR, Hill PR, et al. Passion and burnout in elite junior soccer players: the mediating role of self-determined motivation. Psychology of Sport \& Exercise 2011; 12:655-661.

41. Hull DC, Williams GA, Griffiths, MD. Video game characteristics, happiness and flow as predictors of addiction among video game players: a pilot study. Journal of Behavioral Addictions 2013; 2:145-152.

42. Charlton JP, Danforth ID. Distinguishing addiction and high engagement in the context of online game playing. Computers in Human Behavior 2007; 23:1531-1548.

43. Mentzoni RA, Bronborg GS, Molde H, et al. Problematic video game use: estimated prevalence and associations with mental and physical health. CyberPsychology, Behavior, \& Social Networking 2011; 14:591-596.

Address correspondence to: Dr. Andres Chamarro Faculty of Psychology Universitat Autónoma de Barcelona $B$ Building, Campus of Bellaterra 08193 Bellaterra Spain

E-mail: andres.chamarro@uab.es 